\title{
Mechanisms, Imaging, and Therapy in Stroke Recovery
}

\author{
Changhong Xing ${ }^{1}$ (D) $\cdot$ Kazuhide Hayakawa $^{1} \cdot$ Eng H. Lo $^{1}$
}

Received: 23 September 2016 / Accepted: 27 September 2016 / Published online: 7 October 2016

(C) Springer Science+Business Media New York 2016

Although the majority of phase II/III clinical trials of neuroprotective drugs have failed, recent clinical trials of endovascular recanalization using mechanical thrombectomy were proved effective for acute stroke patients with large vessel occlusions [1-7]. Absolute improvement with endovascular therapy has been found to range between 13.5 to $31 \%$, whereas thrombolytics alone also significantly improve patient functional independence, but to a lesser degree [8]. A meta-analysis provided evidence that for eligible patients with acute ischemic stroke in the setting of large vessel occlusions, outcomes were improved by endovascular intervention combined with medical management, including IV tissue plasminogen activator [9]. Along with recent trends showing a relative reduction in stroke mortality by over $30 \%$ [10], these recent advances now make it even more important to dissect the mechanisms of post-stroke recovery and develop efficacious therapies to reduce disability in survivors of acute ischemic stroke.

Profound cellular and biochemical remodeling take place in the brain following an ischemic stroke, and some of these endogenous mechanisms of cerebral plasticity and neurological recovery may be stimulated with behavioral rehabilitation and non-invasive brain stimulation [11-14]. Recovery from stroke is a multifaceted process, and clinical advances continue to be achieved. Current experimental and clinical stroke research focus on the restoration of motor functions [15-20]. By contrast, sensory deficits, cognitive impairment, and depression are less studied, even though these phenomena would have a major impact on stroke recovery [20]. Neurorehabilitative training

Changhong Xing

XING.CHANGHONG@mgh.harvard.edu

1 Department of Radiology and Neurology, Massachusetts General Hospital, Harvard Medical School, Charlestown, MA 02129, USA has improved clinical recovery of stroke patients in part by augmenting peri-lesional motor plasticity [21-23], but how to adapt these approaches for improving sensory and cognitive recovery remains to be fully investigated. Multiple neuroimaging techniques can now be used to visualize stroke-related structural and functional changes, but more work is required to fully integrate these imaging methods with standard of care to predict and maximize recovery of function [24].

In this special issue, we have sought reviews from established experts to explore the frontiers of basic mechanisms, advanced neuroimaging, and potential translational interventions that might be able to promote neurological recovery after ischemic stroke. The first two papers focus on the mechanisms of neurogenesis and axonal repair after stroke. Koh et al. [25] discuss ways to stimulate neurogenesis after stroke and survey ongoing clinical trials focusing on enhancing neurogenesis. Egawa et al. [26] discuss the mechanisms underlying axonal degeneration and potential targets that may promote axonal regeneration after brain injury.

The third paper asks whether and how some of these substrates and signals of remodeling after stroke may be quantified with in vivo imaging. In this translational paper, Mandeville et al. [27] review the principles and applications of MRI methods in stroke research, including the transition from acute to chronic imaging, preclinical, and clinical imaging to determine tissue viability, vascular remodeling, structural connectivity of major white matter tracts, and task-based and resting-state fMRI during the stroke recovery process.

Finally, the last three papers turn to potential therapeutic opportunities for promoting functional recovery after stroke. Cassidy et al. [28] summarize the spontaneous and treatmentinduced mechanisms driving post-stroke recovery while underscoring the utility of biomarkers that may help guide therapy development. Jeanneret et al. [29] review plasticityinduced changes in dendritic spines that are associated with 
neurological improvement after acute ischemic stroke, with a special emphasis on the role of tissue-type plasminogen activator (tPA) and urokinase-type plasminogen activator (uPA) in this process. Lim et al. [30] highlight the use of novel biomaterials as an enabling tool and important therapeutic strategy for cell transplantation and drug/protein delivery and further discuss advances in biomaterial design that can potentially be translated for the stroke patient.

Taken together, these reviews document the current understanding and emerging frontiers of mechanisms and therapeutic strategies that contribute to neuroplasticity and functional recovery after acute ischemic stroke. We hope that the collection of articles in this special issue will provide a conceptual framework to guide hypothesis-generation for and future studies of functional recovery following stroke.

\section{Compliance with Ethical Standards}

Conflict of Interest The authors declare that they have no competing interests.

\section{References}

1. Linfante I, Cipolla MJ. Improving reperfusion therapies in the era of mechanical thrombectomy. Transl Stroke Res. 2016;7(4):294-302.

2. Berkhemer OA, Fransen PS, Beumer D, van den Berg LA, Lingsma $\mathrm{HF}$, Yoo AJ, et al. A randomized trial of intraarterial treatment for acute ischemic stroke. N Engl J Med. 2015;372(1):11-20.

3. Goyal M, Demchuk AM, Menon BK, Eesa M, Rempel JL, Thornton $\mathrm{J}$, et al. Randomized assessment of rapid endovascular treatment of ischemic stroke. N Engl J Med. 2015;372(11):1019-30.

4. Campbell BC, Mitchell PJ, Kleinig TJ, Dewey HM, Churilov L, Yassi N, et al. Endovascular therapy for ischemic stroke with perfusion-imaging selection. N Engl J Med. 2015;372(11):1009-18.

5. Saver JL, Goyal M, Bonafe A, Diener HC, Levy EI, Pereira VM, et al. Stent-retriever thrombectomy after intravenous t-PA vs. t-PA alone in stroke. N Engl J Med. 2015;372(24):2285-95.

6. Jovin TG, Chamorro A, Cobo E, de Miquel MA, Molina CA, Rovira A, et al. Thrombectomy within 8 hours after symptom onset in ischemic stroke. N Engl J Med. 2015;372(24):2296-306.

7. Henninger N, Fisher M. Extending the time window for endovascular and pharmacological reperfusion. Transl Stroke Res. 2016;7(4):284-93.

8. Lapchak PA. Critical early thrombolytic and endovascular reperfusion therapy for acute ischemic stroke victims: a call for adjunct neuroprotection. Transl Stroke Res. 2015;6(5):345-54.

9. Chen CJ, Ding D, Starke RM, Mehndiratta P, Crowley RW, Liu $\mathrm{KC}$, et al. Endovascular vs medical management of acute ischemic stroke. Neurology. 2015;85(22):1980-90.

10. Shi Y, Leak RK, Keep RF, Chen J. Translational stroke research on blood-brain barrier damage: challenges, perspectives, and goals. Transl Stroke Res. 2016;7(2):89-92.
11. Hermann DM, Chopp M. Promoting neurological recovery in the post-acute stroke phase: benefits and challenges. Eur Neurol. 2014;72(5-6):317-25.

12. Hermann DM, Chopp M. Promoting brain remodelling and plasticity for stroke recovery: therapeutic promise and potential pitfalls of clinical translation. Lancet Neurol. 2012;11(4):369-80.

13. Kubis N. Non-invasive brain stimulation to enhance post-stroke recovery. Front Neural Circuits. 2016;10:56.

14. Hara T, Abo M, Kobayashi K, Watanabe M, Kakuda W, Senoo A. Effects of low-frequency repetitive transcranial magnetic stimulation combined with intensive speech therapy on cerebral blood flow in post-stroke aphasia. Transl Stroke Res. 2015;6(5):365-74.

15. Lo AC, Guarino PD, Richards LG, Haselkorn JK, Wittenberg GF, Federman DG, et al. Robot-assisted therapy for long-term upperlimb impairment after stroke. N Engl J Med. 2010;362(19):177283.

16. Wolf SL, Thompson PA, Winstein CJ, Miller JP, Blanton SR, Nichols-Larsen DS, et al. The EXCITE stroke trial: comparing early and delayed constraint-induced movement therapy. Stroke. 2010;41(10):2309-15.

17. van de Port IG, Wevers LE, Lindeman E, Kwakkel G. Effects of circuit training as alternative to usual physiotherapy after stroke: randomised controlled trial. BMJ. 2012;344:e2672.

18. Winstein CJ, Wolf SL, Dromerick AW, Lane CJ, Nelsen MA, Lewthwaite R, et al. Interdisciplinary comprehensive arm rehabilitation evaluation (ICARE): a randomized controlled trial protocol. BMC Neurol. 2013;13:5.

19. Duncan PW, Sullivan KJ, Behrman AL, Azen SP, Wu SS, Nadeau SE, et al. Body-weight-supported treadmill rehabilitation after stroke. N Engl J Med. 2011;364(21):2026-36.

20. Jolkkonen J, Kwakkel G. Translational hurdles in stroke recovery studies. Transl Stroke Res. 2016;7(4):331-42.

21. Seitz RJ, Donnan GA. Recovery potential after acute stroke. Front Neurol. 2015;6:238.

22. Cumming TB, Thrift AG, Collier JM, Churilov L, Dewey HM, Donnan GA, et al. Very early mobilization after stroke fast-tracks return to walking: further results from the phase II AVERT randomized controlled trial. Stroke. 2011;42(1):153-8.

23. Ploughman M, Austin MW, Glynn L, Corbett D. The effects of poststroke aerobic exercise on neuroplasticity: a systematic review of animal and clinical studies. Transl Stroke Res. 2015;6(1):13-28.

24. Auriat AM, Neva JL, Peters S, Ferris JK, Boyd LA. A review of transcranial magnetic stimulation and multimodal neuroimaging to characterize post-stroke neuroplasticity. Front Neurol. 2015;6:226.

25. Koh SH, Park HH. Neurogenesis in stroke recovery. Transl Stroke Res. 2016.

26. Egawa N, Lok J, Washida K, Arai K. Mechanisms of axonal damage and repair after central nervous system injury. Transl Stroke Res. 2016.

27. Mandeville ET, Ayata C, Zheng Y, Mandeville JB. Translational MR neuroimaging of stroke and recovery. Transl Stroke Res 2016.

28. Cassidy JM, Cramer SC. Spontaneous and therapeutic-induced mechanisms of functional recovery after stroke. Transl Stroke Res 2016.

29. Jeanneret V, Yepes M. The plasminogen activation system promotes dendritic spine recovery and improvement in neurological function after an ischemic stroke. Transl Stroke Res 2016.

30. Lim TC, Spector, M. Biomaterials for enhancing CNS repair. Transl Stroke Res 2016. 